\title{
Breve Análise de "Música para as Crianças" (1977) do Compositor português Fernando Lopes-Graça (1906-1994)*
}

\author{
António Sérgio Azevedo
}

\section{Preâmbulo}

Compostas em 1977, estas vinte e oito pequenas peças infantis representam, no imenso catálogo de Lopes-Graça, aquela faceta didática e lúdica que sempre esteve presente na sua obra de compositor. Artista profundamente consciente do seu papel na sociedade enquanto músico interveniente, tanto do ponto de vista político como social e cultural, Graça sempre utilizou a sua Arte para o embate ideológico e para o crescimento cultural de todo um Povo. Obras mais típicas dessa intervenção são as célebres "Canções e Marchas", mais tarde conhecidas como "Canções Heróicas", quase todas as peças para coros amadores (entre as quais as "Canções Regionais Portuguesas"), e ainda coleções para piano como o "Álbum para jovens pianistas" e as vinte e oito miniaturas infantis, que aqui irão ser o objeto de uma análise mais detalhada.

Gostaria de louvar o interesse demonstrado pelos colegas deste nosso país irmão, o Brasil, na divulgação e uso escolar da obra de um dos maiores compositores já nascidos em Portugal.

* Cópia de "Música para as Crianças", a nós entregue em 1983 por Lopes-Graça, encontra-se depositado no Depto. de Música da ECA-USP. 


\section{Sobre algumas facetas do estilo de Fernando Lopes-Graça (n. Tomar, 17.XII.1906)}

Não podemos desdenhar a influência dos celebérrimos seis volumes do Mikrokosmos de Béla Bártók (1881-1945) na produção destinada à pedagogia pianística de Lopes-Graça, bem como a influência geral que o compositor magiar exerceu durante toda a sua carreira sobre a obra e a postura mental e social do mestre português, influência que este é o primeiro a reconhecer e confirmar com o maior prazer. Essa influência é, no entanto, no que respeita à música, bem mais de ordem técnica do que estilística. De Bártók absorveu Lopes-Graça a maestria no tratamento da música popular (neste caso, ibérica), as técnicas de recolha e classificação dessa mesma música (juntamente com Michel Giacometti), além de uma grande vivacidade rítmica e um estilo pianístico duro e percutido. Podemos ainda citar um Stravinsky ou um Manuel de Falla entre os nomes importantes deste século que, naturalmente, significaram algo para a formação artística de Lopes-Graça.

\section{Algumas características técnicas gerais}

Ao iniciar esta breve análise de cada uma das vinte e oito peças que constituem o Álbum, irei resumir algumas das particularidades técnicas passíveis de se encontrarem com maior freqüência nestas obras didáticas:

a) uso de escalas modais, extremo cromaticismo, escalas por tons, simétricas, pentatônicas ou octatônicas: n. ${ }^{\circ} 1,24,26,27$;

b) uso de sobreposição ou justaposição de tonalidades e/ou modos diferentes (bitonalidade ou bimodalidade, politonalidade, polimodalidade, pandiatonicismo etc.): $\mathrm{n} .{ }^{\circ} 17,22,23$;

c) uso de melodias genuinamente folclóricas ou de cariz popular, pertencentes já ao chamado "folclórico imaginário", fase última da absorção dos caracteres étnicos da música de todo um Povo: n. ${ }^{\circ} 12,16,19,25$; 
d) uso de ostinatos melódicos e rítmicos, mudanças freqüentes de compasso, metros mistos, assimétrico etc.: $\mathrm{n} .{ }^{\circ} 18,20,28$.

\section{Análise das 28 peças do Álbum "Música de piano para crianças"(1977)}

PEÇA n. ${ }^{\circ} 1$... Estudo $n .{ }^{\circ} 1$

A primeira peça desenvolve uma melodia muito simples, com um certo cariz gregoriano, no modo Lá diatônico, e procede por paralelismos de $5 .{ }^{\text {a }}$ sem alguma mudança, o que confere à música um certo sabor medieval (organum primitivo). Estes paralelismos ocorrem também, como é sabido, nos conjuntos populares corais de um modo muitas vezes inconsciente, tomando desse fato o tipismo rústico que esta peça ostenta:

\section{Ex. 1a (Lopes-Graça)}

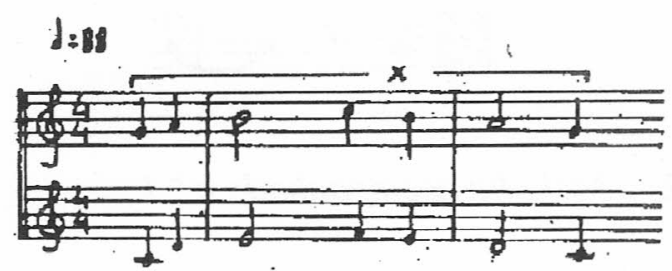

Ex. 1b (Mikrokosmos I, $n .^{\circ} 11$ )

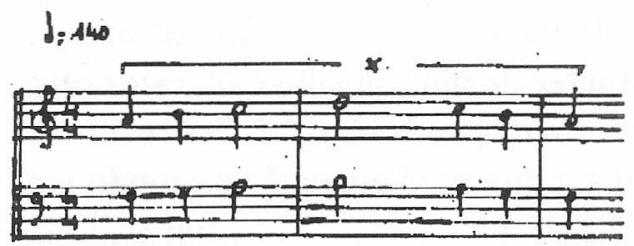

Usual também dentro da música de Lopes-Graça é a técnica utilizada nesta obra para desenvolver, dentro de uma estrutura ostinata, a melodia inicial. Fragmentos da mesma vão sendo sucessivamente alongados de modo assimétrico, até resultar uma grande polarização do eixo principal, Lá: 
Ex. $2 a$
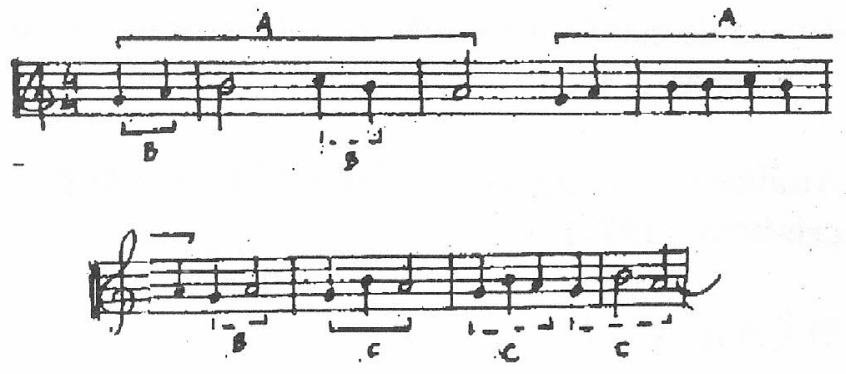

Ex. 2b
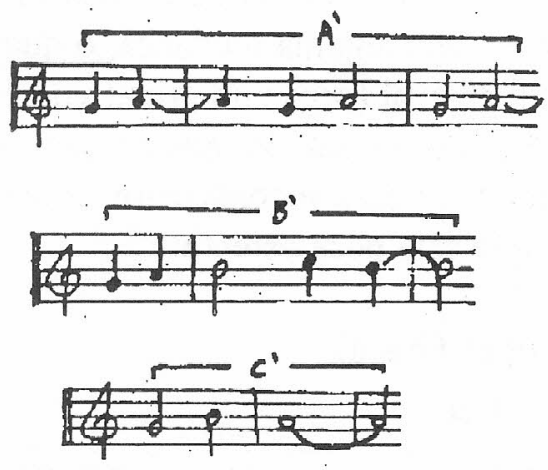

PEÇA n. ${ }^{\circ} 2$... Melodia acompanhada $n .^{\circ} 1$

Lopes-Graça não foge, nesta coletânea, aos tipismos pedagógicos, e, muito naturalmente, algumas destas peças seguem modelos de escrita utilitária do ponto de vista da pura técnica pianística (o que é de esperar de um trabalho com estes objetivos). É este o caso da Melodia acompanhada $n .^{\circ} 1$. Sobre um baixo de Fá e uma

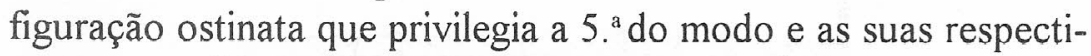
vas quartas "duras" e "suaves" (Si bemol e Si bequadro), desenvolve-se uma melodia no mesmo modo que marcha também com o auxílio freqüente de ambas as quartas melódicas. A cadência resume por aumentação o último membro da melodia (Ex. 3a) e acentua a alternância modal Si bemol / Si bequadro, juntamente com o uso do ornato superior maior, tão característico de alguma da nossa música popular (Ex. 3b): 
Ex. 3a

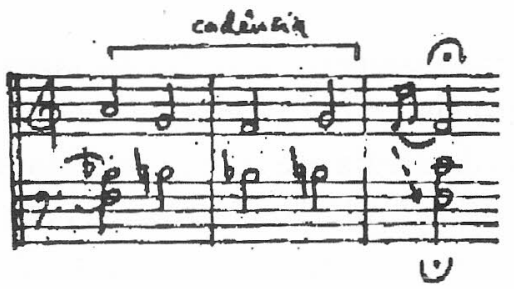

Ex. $3 b$

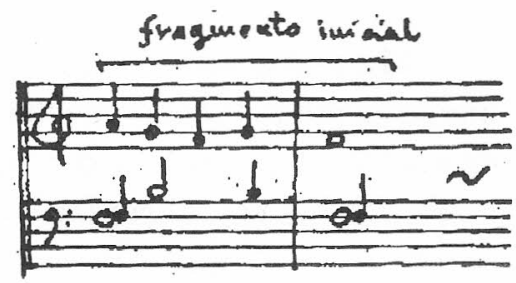

PEÇA n. ${ }^{\circ} 3$... Estudo $n .^{\circ} 2$

Pequena peça muito singela em Sol, com características modais, baseada em um ostinato $\mathrm{T} / \mathrm{D}$ no grave, e em uma frase descendente no agudo. A técnica, que consiste em repetir a mesma frase com aumentação ou diminuição irregulares perto do final, é novamente usada (ver Estudo $n .^{\circ}$ l). A obra fica suspensa por uma nota de passagem que se mantém (Lá), não resolvendo portanto na tônica Sol, tal como seria de esperar.

PEÇA n. ${ }^{\circ} 4$... Melodia acompanhada $n .^{\circ} 2$

Em contraste com a primeira melodia acompanhada, o acompanhamento passa agora para a mão direita e a melodia, para a esquerda. A tonalidade de Dó é aqui evidente, embora pejada de pormenores harmônicos e contrapontísticos de cariz rústico $\left(4 .^{a} \mathrm{e}\right.$ 5. ${ }^{a}$ paralelas, dissonâncias não resolvidas etc.). É normal, em LopesGraça, o evitar cadências convencionais, deixando antes uma surpresa para finalizar (Ex. 4).

\section{Ex. 4}

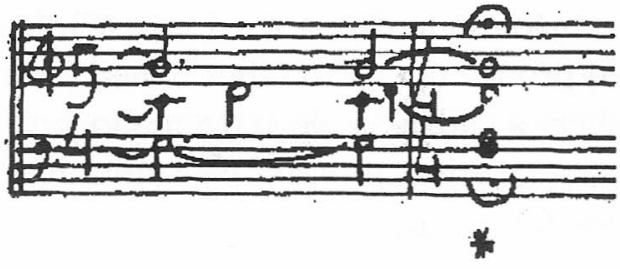


PEÇA n..$^{\circ} 5$... Melodia acompanhada $n .^{\circ} 3$

Mais uma melodia com acompanhamento, invertendo novamente as vozes. $\mathrm{O}$ acompanhamento em Lá $\mathrm{m}$ sobre pedal de tônica sugere apenas o $1 .^{\circ}$ e o $5 .^{\circ}$ graus da escala até cinco compassos do fim. Sobre este baixo faz Lopes-Graça ouvir uma melodia polarizada na dominante ornamentada com o $4 .^{\circ}$ grau da escala subido e diatônico em justaposição, o que produz um simulacro de escala exótica perto do final com a adição de um $3{ }^{\circ}$ grau subido (Ex. 5).

\section{Ex. 5}

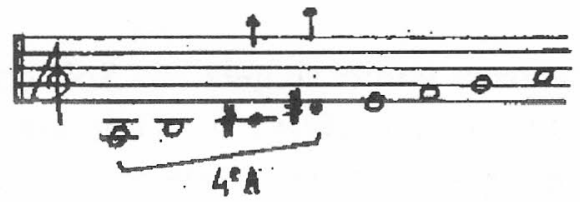

PEÇA n. ${ }^{\circ} 6$... Estudo n. ${ }^{\circ} 3$

Um simples estudo de movimento paralelo à $8 .{ }^{a}$, com constante alternância de metro. A iniciar a coda, no 31.0 compasso, uma idéia construída dentro do âmbito da $5 .{ }^{a}$ perfeita em que toda a peça se move sugere um pequeno cânone à $8 .^{\mathrm{a}}$, após o que a peça termina com o tipo de aumentação/diminuição de um intervalo simples, técnica já observada em peças anteriores. $\mathrm{O}$ acorde final introduz a surpresa de um Dó sustenido contra um Dó bequadro, produzindo assim um efeito de suspensão bimodal.

PEÇA n. ${ }^{\circ} 7$... Um bocadinho triste

Eis, juntamente com o $1 .^{\circ}$ estudo, a peça mais singela deste álbum. Estrutura-se em um contraponto simples de 1. ${ }^{a}$ espécie em brancas, ambas as mãos reduzidas a um âmbito de 5. a (Lá/Mi). A alternância na mão esquerda entre a $3{ }^{a} \mathrm{~m}$ e a $3 .{ }^{\mathrm{a}} \mathrm{M}$ (Dó bequadro e Dó sustenido) produz um certo sabor bimodal maior e menor. De salientar também a cadência, de certo modo suspensa pela $1 .^{a}$ inversão e de características picardas pela utilização final do Dó sustenido que, por fim, se afirma. 
PEÇA n. ${ }^{\circ} 8$... Simples canção

Mais um estudo para os cinco dedos. No modo de Mi e salientando pela configuração melódica o trítono Si/Fá. Pode-se dividir em duas partes, aliás bem delimitadas pela mudança do imperante $5 / 4$ noutros metros. Termina esta pequena obra com um acorde baseado em quintas perfeitas sobrepostas: Lá-Mi-Si (Mi).

PEÇA n. ${ }^{\circ} 9$... Estudo n. ${ }^{\circ} 4$

Um estudo para o movimento contrário, de cariz polidiatônico, estrutura-se em quatro pequenas seções, sendo a terceira ("a tempo") uma ornamentação da $1 .{ }^{a}$ e a $4 .{ }^{a}$ UMA Coda em valores mais longos, com o uso típico da repetição de um motivo na cadência (Ex. 6).

Ex. 6

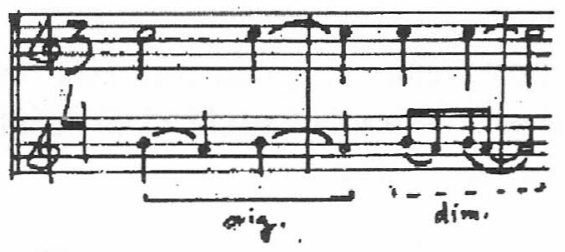

PEÇA n. ${ }^{\circ} 10$... Recordação

S Jbre uma pedal de Lá T/D, desenvolve-se uma singela melodia em arpejos formados pelos $1 .^{\circ}, 4 .^{\circ}, 7 .^{\circ} \mathrm{e} 2 .^{\circ}$ (napolitano) graus da escala. A partir do $9 .^{\circ}$ compasso, o baixo muda para uma outra figuração ostinata em graus conjuntos, com a qual é formada a cadência (sobre o intervalo "dissonante" da quarta perfeita).

PEÇA n. ${ }^{\circ} 11 \ldots$ Estudo n. ${ }^{\circ} 5$

Mais um estudo, desta vez de sabor pentatônico, sobre a escala Dó-Ré-Mi-Sol-Lá. A partir do compasso 14, Lopes-Graça introduz alterações cromáticas que sugerem o modo de Sol transposto para Dó, após o que, no "poco rit.", faz cadência com Ré 
bemol e Si natural (6. aumentada, $\not{\not}$ ) - Ex. 7. Este acorde resolve para a tônica no "a tempo", sendo o início da peça recapitulado com alargamento da 2. ${ }^{a} \mathrm{M}$ Lá-Sol e a cadência feita com o 7. ${ }^{\circ}$ grau baixado (modo de Sol transposto) e com o picante Mi bemol/Mi natural com funções colorísticas. A música acaba por repousar em um simples $I_{6}$.

\section{Ex. 7 (acorde - 6. aumentada... )}
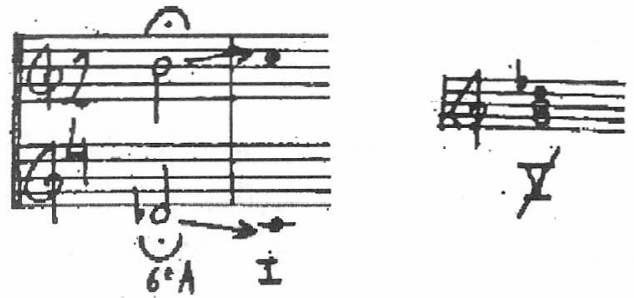

PEÇA n. ${ }^{\circ} 12$... Canção da Serra da Estrela

Não resistimos a citar integralmente esta belíssima melodia popular portuguesa da Serra da Estrela à laia de introdução, usada tal qual por Lopes-Graça (Ex. 8):

Ex. 8
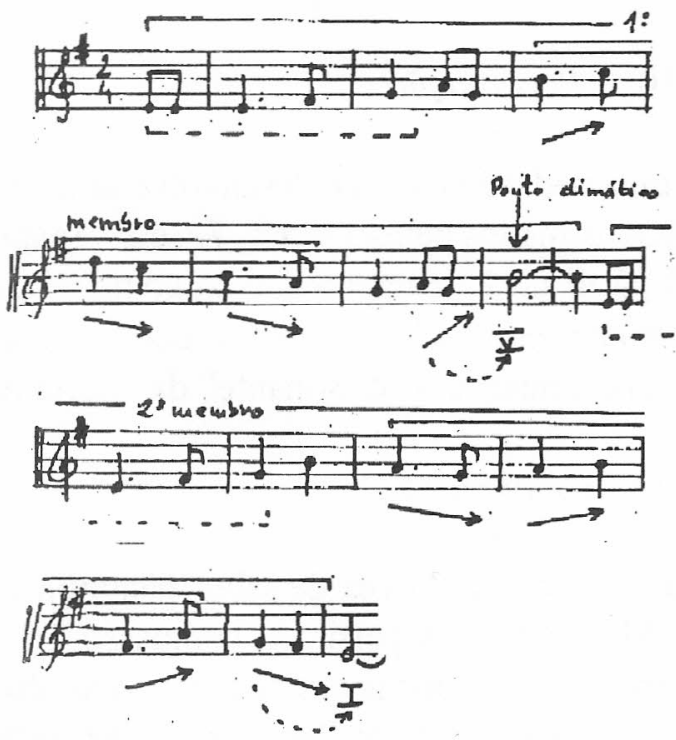
Esta peça inicia-se com a repetição do $\mathrm{Mi}$, sobre o qual a melodia é construída, como que a antecipar a si mesma. A intenção do autor neste passo será com certeza a simulação de um pequeno tambor campesino, que preludia ritmicamente a canção (neste caso, o ritmo anacrúsico mais característico da mesma $\int \mathcal{L}$ J).

O primeiro membro da canção é então ouvido depois de uma suspensão no $\mathrm{Mi}$, acompanhado de um contraponto simples mas dissonante, que faz lembrar por momentos alguns tipos de polifonia eslava dissonante (o canto "znameni" ou os surpreendentes motetos medievais russos com as suas segundas e sétimas paralelas).

A cadência utiliza o repouso da $5{ }^{\mathrm{a}}$ perfeita antes de se iniciar o $2{ }^{\circ}$ membro da melodia, o qual (como é hábito em Lopes-Graça) é repetido "piú piano" uma $8 .{ }^{\mathrm{a}}$ mais aguda e ornamentado com um ornato superior na respectiva cadência:

\section{(pequeno exemplo)}

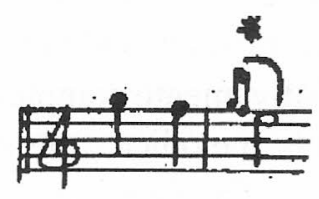

De salientar que o contraponto é diverso na repetição, sendo esta variedade uma característica do compositor, a quem repugnam as repetições literais ou "redites", tantas vezes indício de pouca imaginação criativa...

A coda consiste na repetição literal do Mi do início e do seu ritmo característico, sendo a cadência, no entanto, mais rica do que as precedentes a duas vozes (fazendo intervalos harmônicos de respectivamente $5 .{ }^{a} \mathrm{P}, 3 .{ }^{\mathrm{a}} \mathrm{M} \mathrm{e} 4 .{ }^{\mathrm{a}} \mathrm{P}$ ). $\mathrm{O}$ acorde de três sons junta a quarta perfeita e a aumentada, criando uma sensação de frustração do repouso esperado (a $5 .^{\text {a }}$ ou a $8 .{ }^{a}$ ?).

PEÇA n. ${ }^{\circ} 13$... Estudo n. ${ }^{\circ} 6$

Pecinha muito singela, completamente diatônica, ritmicamente insistindo apenas nas síncopes regulares (por vezes irregulares 
em cadências, ver compassos 9 e 16), enquanto que melodicamente estrutura-se exclusivamente em pequenos movimentos escalares diretos ou quebrados. De salientar que a melodia na mão direita produz quase sempre a inversão diatônica da mão esquerda.

PEÇA n. ${ }^{\circ} 14$... Cânone a 2 vozes

A escrita de pequenos cânones à 8 . $^{\mathrm{a}}$ ou à $5{ }^{\mathrm{a},}$ e mesmo a outros intervalos mais complexos, é comum a muitos métodos de piano modernos, uma vez que esses mesmos cânones introduzem sutilmente o aluno nos segredos da arte contrapontística, sem por isso descurarem os objetivos pianísticos a atingir. Formalmente, este cânone divide-se em quatro seções bem distintas: "Sujeito", com pequeno alargamento e frase cadencial até à suspensão (comp. 1 a 18), "Reexposição" modificada (comp. 19 a 28) e "Coda", tema por aumentação e cadência final. A razão porque coloco estas seções entre parêntesis deve-se ao fato de a peça ser extremamente curta, embora dela se possam extrair certos dados formais "condensados" e até relativamente complexos. Note-se a predominância da 4. Aumentada melódica, que é usada para terminar a peça na forma harmônica (Ex. 9a e 9b):

Ex. 9a

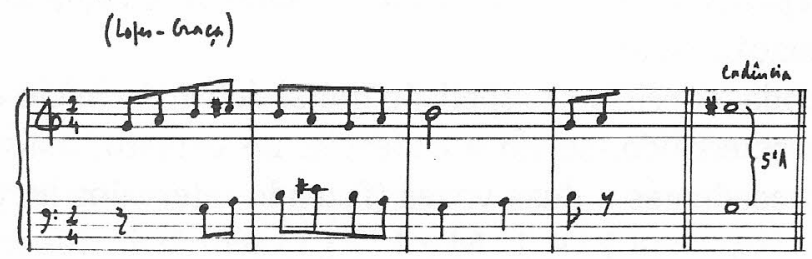

Ex. $9 b$

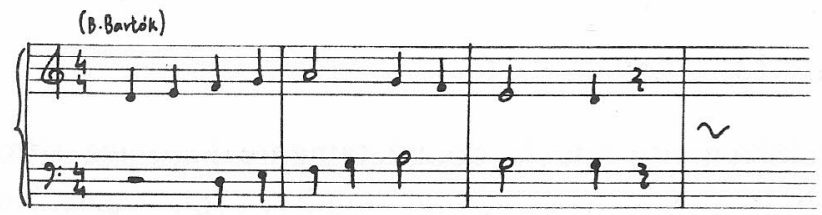


PEÇA n. ${ }^{\circ} 15$... Melodia acompanhada $n .^{\circ} 4$

Enquanto Béla Bártók, no $1 .^{\circ}$ volume do Mikrokosmos, utiliza quase exclusivamente técnicas de escrita de índole contrapontística para obter independência de mãos, já Lopes-Graça não desdenha as fórmulas mais tipicamente "clássicas", como esta Melodia acompanhada $n .^{\circ} 4$. quarta reiteração da mesma textura musical, apenas pode significar que Lopes-Graça concede uma certa importância a uma fórmula aparentemente tão gasta e corriqueira. A razão profunda parece-nos ser a grande facilidade e propensão natural da mesma para o exercício simples mas eficaz das técnicas bitonais e bimodais, como é o caso.

O acompanhamento desta melodia aparece na voz superior e consiste apenas em um simples acorde de Sol M arpejado. Podemos comparar o início da peça $n .^{\circ} 3$ com o início desta, uma vez que procedem quase do mesmo modo. A melodia que Lopes-Graça contrapõe sugere a Dominante, embora com a alteração modal Maior/menor, tornando assim audivel uma clara textura bitonal com alterações modais de percurso (Ré $\mathrm{M} / \mathrm{m}$ ). Depois de um ponto cadencial no compasso 23, o compasso 24 assume uma espécie de reexposição através da repetição do início. Desta vez, porém, a continuação é diversa, aparecendo a alteração para Sol m, enquanto a melodia introduz um Sol sustenido que provoca o trítono no seio de uma melodia até aí pacificamente diatônica...

PEÇA n. ${ }^{0} 16$... Canção alentejana

A complexidade contrapontística e textural desta peça, baseada numa melodia popular do Alentejo, não a colocam porventura ao alcance de todas as crianças aprendizes do piano. Efetivamente, embora a forma seja construída a partir da repetição (uma 8. ${ }^{a}$ para o grave) do tema popular com um acompanhamento ostinato ao invés do contraponto inicial, a exigência de leitura é bastante grande. 
A alternância Dó bequadro / Dó sustenido no intervalo de 5. ${ }^{\mathrm{a}}$ do acompanhamento final é muito característica. Novamente é a clareza da 5. ${ }^{\text {a }}$ perfeita obscurecida pela "inquietude" da 5. diminuta. De notar, igualmente, a cadência que introduz um Mi bemol estranho à modalidade, e o efeito dissonante (e não conclusivo!) dos últimos acordes (Ex. 10):

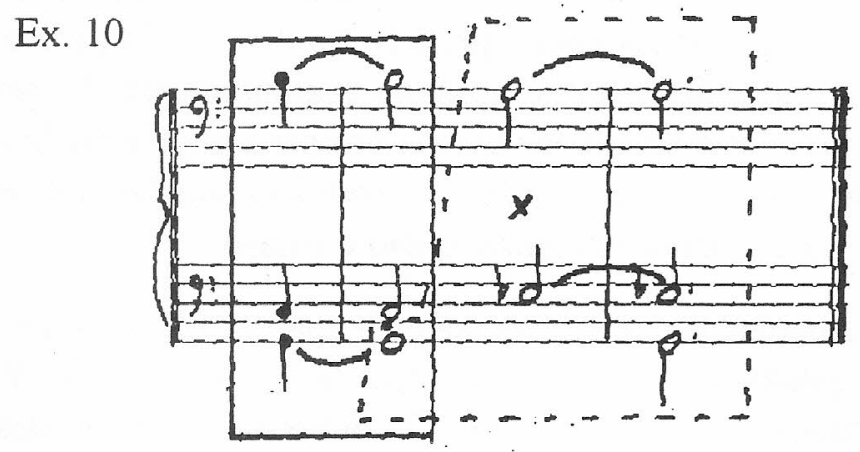

PEÇA n. ${ }^{\circ} 17$... Brincadeira

Esta pequena "brincadeira" estende-se até o ato da composição em si, pois o que temos aqui é a deliciosa sobreposição de Dó Maior na mão direita (que entoa uma singela melodia de cariz folclorizante) e das teclas negras na mão esquerda, que sugerem a escala pentatônica (sem o Ré sustenido ou Mi bemol)...

PEÇA n. ${ }^{\circ} 18$... Baixo obstinado

Essencialmente um estudo rítmico, que usa um baixo ostinato (obstinado) no grave do piano em compasso 5/4. A mão direita faz ouvir uma melodia fragmentada, que é tocada juntamente com uma pedal de Dominante, Sol. O modo sugerido é o de Sol transposto para dó (com um Si bemol portanto). Perto do final (comp. 18), a introdução de um Mi bemol faz cambiar a sensação modal para Ré, embora continue a meșma transposição para Dó. A cadência faz ouvir essas duas alterações sobre o pedal de Dó (a tônica da transposição) e ainda um terceiro intruso, Ré bemol (Ex. 11): 
Ex. 11

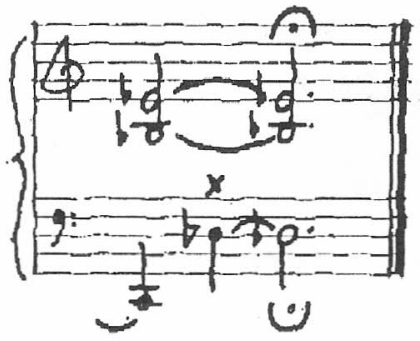

PEÇA n. ${ }^{\circ} 19$... Canto dos batedores de água

Esta simples e bela melodia, no modo de Ré transposto para Mi, forma toda a pecinha, sempre em diferentes harmonizações. É, sem dúvida, uma das mais belas obras deste álbum. A melodia é formada por duas frases, cada uma com dois membros distintos (Ex. 12).

Lopes-Graça harmoniza-a da sua maneira peculiar, freqüentemente dissonante e bitonal/bimodal. Note-se a tendência para a "claridade" do modo Maior nos últimos cinco compassos, através das alterações Dó sustenido e Ré sustenido (VI e VII). A cadência faz ouvir um duplo ornato superior e inferior cromático sobreposto à $5 .{ }^{\mathrm{a}}$ perfeita do modo (Ex. 13).

Ex. 12
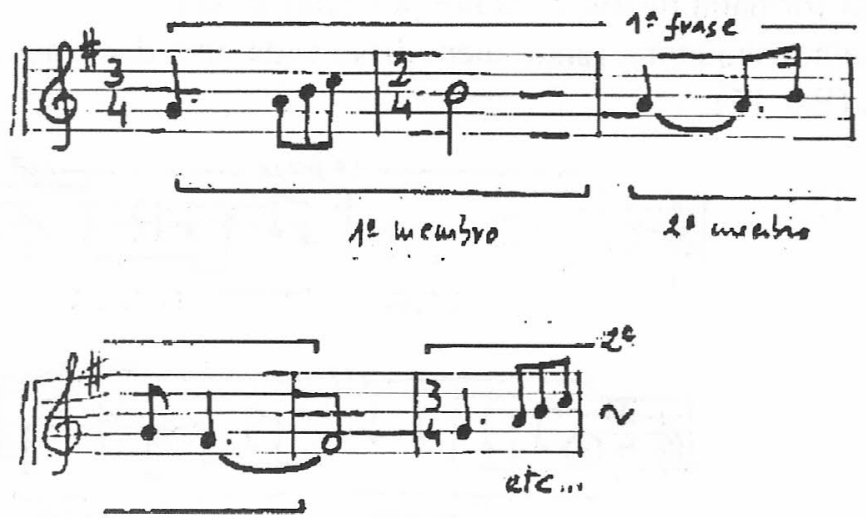
Ex. 13

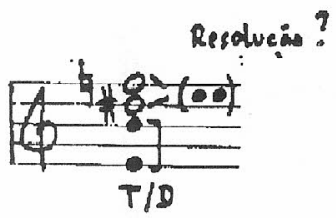

PEÇA n. ${ }^{\circ} 20$... Jogo de terceiras

Este jogo de terceiras pertence igualmente a outro grupo típico da escrita para piano com objetivos didáticos. A alternância de terceiras nas duas mãos, ainda desta vez com o recurso à bimodalidade (Mi M/m) (Ex. 14a). Como na maior parte destas obras, a forma é muito simples: A . . A'. . cad.

A 4. ${ }^{a}$ Aumentada aparece mais uma vez a concluir, no que parece ser um ex-libris do compositor, sugerindo com o Sol e o Dó sustenido o acorde de $\mathrm{V}^{7}$ da tonalidade, sem resolução... (Ex. 14b)

Ex. $14 \mathrm{a} / \mathrm{b}$

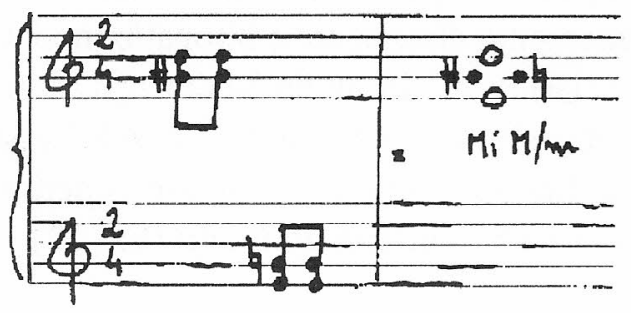

PEÇA n. ${ }^{\circ} 21$... Rosa, a pastorinha

Peça formada melodicamente por duas frases, de caráter antecedente/conseqüente, tendo além disso cada uma dois membros distintos (Ex. 15):

Ex. 15
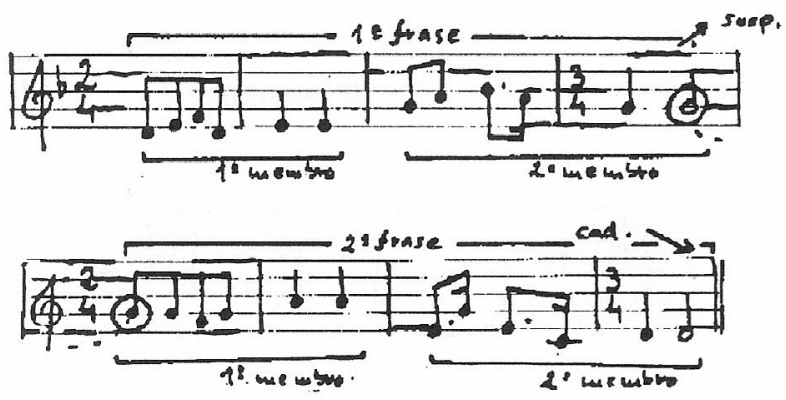
É interessante notar que os pontos cadenciais não são harmonizados segundo os graus que "naturalmente" sugerem, como seria de esperar em compositores mais rotineiros ou de menor técnica e imaginação do que a de um Lopes-Graça. Ao contrário, este inventa sempre deliciosas surpresas harmônicas, que fazem a originalidade destas obrinhas infantis. Senão vejamos (Ex. 16):

Ex. 16

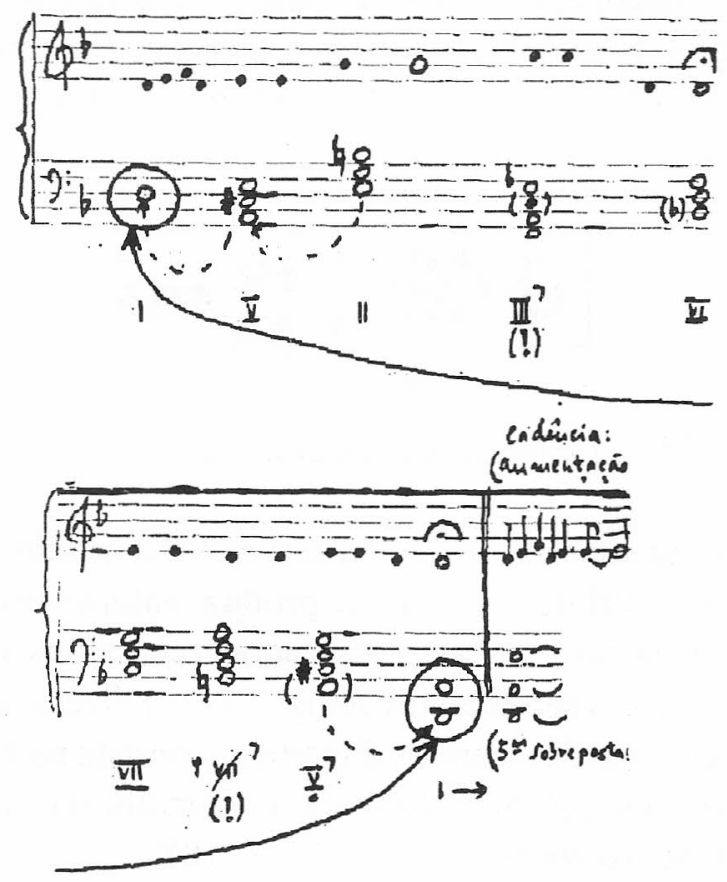

PEÇA n. ${ }^{\circ} 22$... O branco e o preto

Curta pecinha baseada exclusivamente na sobreposição do modo de Lá diatônico e de uma escala pentatônica (notas pretas do teclado). Podemos compará-la à n. ${ }^{\circ} 17$ (Brincadeira), uma vez que o processo composicional é muito semelhante. Do princípio ao fim desta obra, a textura permanece idêntica. Mais uma vez a cadência é extremamente dissonante e suspensiva (Dó sustenido, Dó bequadro, Mi). 
PEÇA n. ${ }^{\circ} 23$... Divagação

Uma atmosfera sonhadoramente raveliana banha esta pequenina peça, cuja missão técnica consiste na alternância das mãos, exclusivamente em terceiras maiores, que a partir do compasso 15 se misturam com terceiras menores, restando apenas estas últimas desde o compasso 22 até a cadência. A textura acórdica é, por isso, vagamente bitonal/bimodal, sem esclarecer efetivamente nenhum pólo básico. Note-se que o agregado harmônico final sugere um acorde de $9 .{ }^{a} \mathrm{~m}$ com $5 .^{a}$ descida e sem a presença da 7. ${ }^{a}$ (Ex. 17):

Ex. 17

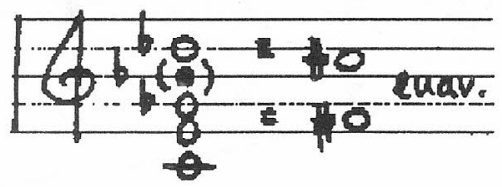

PEÇA n. ${ }^{\circ} 24$... Pequena mísica chinesa

Baseada na sobreposição de uma melodia pentatonal e no acorde de 7. ${ }^{\text {a }}$ sensível de Si M (o que produz, naturalmente, a nível de pitch-class, notas brancas contra notas pretas), esta peça distingue-se das outras semelhantes compostas por diversos autores para as crianças. Uma das maiores diferenças consiste no evitar a escala pentatônica pura, já tão banalizada, e substituir o esperado Ré por um Mi bemol (compassos 23 e 24. Ex. 18):

Ex. 18

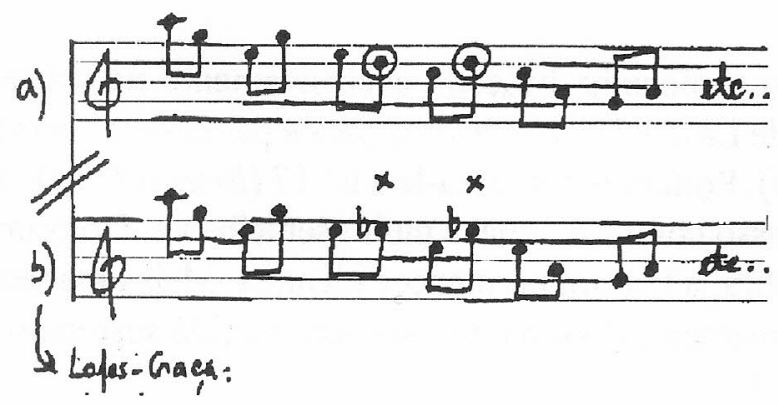


Os compassos finais fazem ouvir uma sobreposição do acorde de 7. ${ }^{a}$ sensível no grave e um acorde de 7. ${ }^{\mathrm{a}}$ menor sobre Lá, produto da verticalização da melodia, no qual se nota a falta do Ré mais uma vez...

PEÇA n. ${ }^{0} 25$... Canção beirã

Mais uma canção popular recolhida por Lopes-Graça, de entre as milhares que recolheu e estudou no seio do povo português.

Contrariamente ao habitual, Lopes-Graça fá-la ouvir apenas uma única vez, com uma pedal intermédia de tônica e um contraponto dissonante cromático no baixo. Fica assim assegurado o caráter rude e campesino da harmonização, tão fresca a singela na sua sofisticação que nos levariam a citar toda a peça, o que não é possível!

Citemos apenas a belíssima cadência em Mi nos compassos 8 a 11 (Ex. 19):

Ex. 19

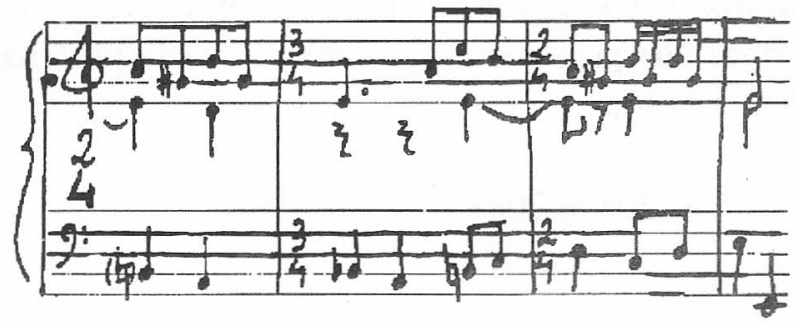

Após esta bela peroração, segue-se imediatamente uma longa e lenta Coda de dez compassos, baseada em fragmentos da melodia. $\mathrm{O}$ acorde final mantém a Subdominante $\mathrm{A}$ no baixo, não resolvida, e sob um Si prolongado (ao invés do esperado Mi) faz LopesGraça ouvir um completamente estranho acorde de Lá Maior...

PEÇA n. ${ }^{\circ} 26$... Pentatonia

Eis agora um exemplo realmente "puro" de pentatonicismo, claramente anunciado no próprio título da obra. Com um caráter 
livremente imitativo, esta peça utiliza exclusivamente as teclas negras do piano, tendo cada voz o âmbito de uma $6{ }^{a} \mathrm{M}$, que se revela ótima para os cinco pequenos dedos das crianças. Como é usual em Lopes-Graça, um tema é enunciado logo de início, sendo depois dele extraídos fragmentos que sofrerão processos de aumentação, diminuição, inversão e outros quanto baste para assegurar ao mesmo tempo variedade e coerência à obra.

PEÇA n. ${ }^{\circ} 27$... Caleidoscópio

Até o $10{ }^{\circ}$ compasso consiste esta peça em um cânone cromático à $4 .{ }^{a}$ inferior (T-D). De notar a ausência de indicação de compasso, o qual oscila livremente entre $3 / 4$ e $2 / 4$ com supremacia do último. a partir do $11 .^{\circ}$ compasso, a textura imitativa desaparece, continuando porém a escrita cromática inicial, privilegiando relações verticais de $2 .{ }^{a}$ É É, sem dúvida, uma das as peças deste ciclo que maiores dificuldades de abordagem coloca a uma criança. Poderemos inclusive comparar o início com o do n. ${ }^{\circ} 91$ do Mikrokosmos de Bártók, para compreendermos até que ponto leva Lopes-Graça este seu (aparentemente) despretensioso álbum (Exs. $20 \mathrm{a}$ e 20b):

Ex. 20á e 20b

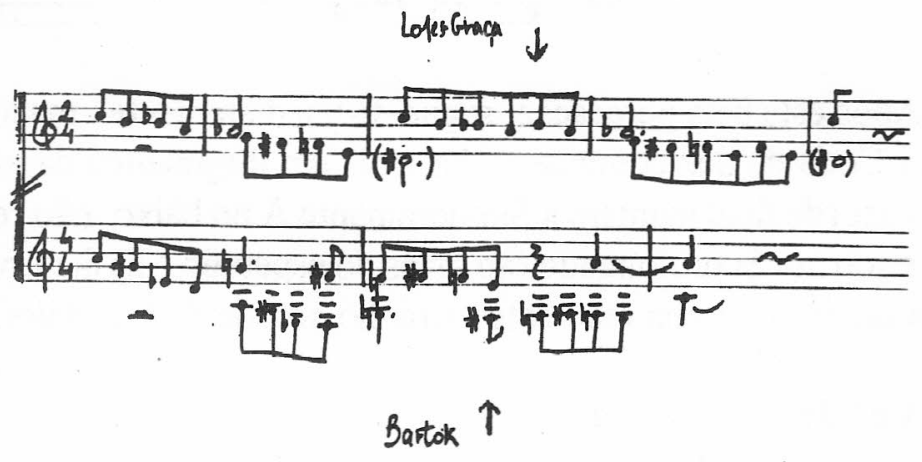

A peroração final é novamente conduzida até uma $5 .^{\text {a diminu- }}$ ta (Mi-Si bemol). 
PEÇA n. ${ }^{\circ} 28$... Tocata

A terminar este admirável conjunto de pequenas obras-primas da escrita pianística para as crianças, encontramos a mais extensa da série (57 compassos). Sendo no entanto bastante rápida (semínima $=160$ ), não é de fato a maior em duração. É porém uma das mais exigentes do ponto de vista teórico e a mais perigosa. Alternância de mãos contínua, freqüente alteração métrica, cromatismos em alternância com sobreposição de ambas as mãos e ainda pequenas polifonias de índole cromática (compassos 16 a 19). Um rápido arpejo põe fim a esta sucessão vertiginosa de colcheias, que vai subindo no registro até terminar uma oitava acima do início com um intervalo de $2 .{ }^{\mathrm{a}} \mathrm{M}$, cadência que já nos é familiar de outras das peças deste álbum e que sugere um duplo ornato cromático a rodear o som principal (Mi), sem resolução...

\section{Conclusão e considerações finais}

A rápida vistoria e análise sucinta destas vinte e oito pecinhas permitem, no entanto, extrair delas várias ilações, claras e convincentes. A mais importante parece-me ser a grande coerência que Lopes-Graça consegue, não só dentro de cada peça mas ao longo de todo o ciclo. Tal deve-se ao constante emprego de técnicas e gestos bem pessoais, os quais (note-se bem), tal como em Bártók ou em Stravinsky, servem não só para a construção de obras importantes de grandes dimensões, como também para a construção da mais ínfima e inocente pecinha ou melodia infantil. Parece-me ser esta a grande lição que, neste caso, Lopes-Graça aprendeu com os grandes músicos (e não só com os do nosso século; veja-se por exemplo as peças fáceis de J. S. Bach!).

Todos os processos técnicos que aqui foram analisados e revelados se aplicam igualmente às obras maiores do mestre português, inclusive as mais abstratas de pensamento ou construção: $2 .^{\circ}$ Quarteto, 14 Anotações, Canto de Amor e de Morte, 5. ${ }^{\mathrm{a}}$ e 6. ${ }^{\mathrm{a}}$ Sonatas para piano etc. 
O estudo e a análise da quase totalidade da obra de Fernando Lopes-Graça está ainda por fazer. A dos outros compositores portugueses de grande estatura (Seixas, Bontempo, entre alguns outros já começaram a ser estudados e publicados há já alguns anos, graças ao esforço de alguns musicólogos e instituições nacionais e até internacionais) permanece nos arquivos poeirentos das bibliotecas, espólios e outras coleções do mesmo tipo...

Possa ele pequeno trabalho ajudar e incentivar outros compositores e musicólogos a realizarem estudos de maior envergadura sobre as obras máximas dos melhores músicos portugueses, entre os quais se conta Fernando Lopes-Graça.

Como seu ex-aluno e grande amigo e apreciador da sua atividade musical ao longo de mais de dez anos de conhecimento pessoal do Maestro, é este o meu voto mais sincero.

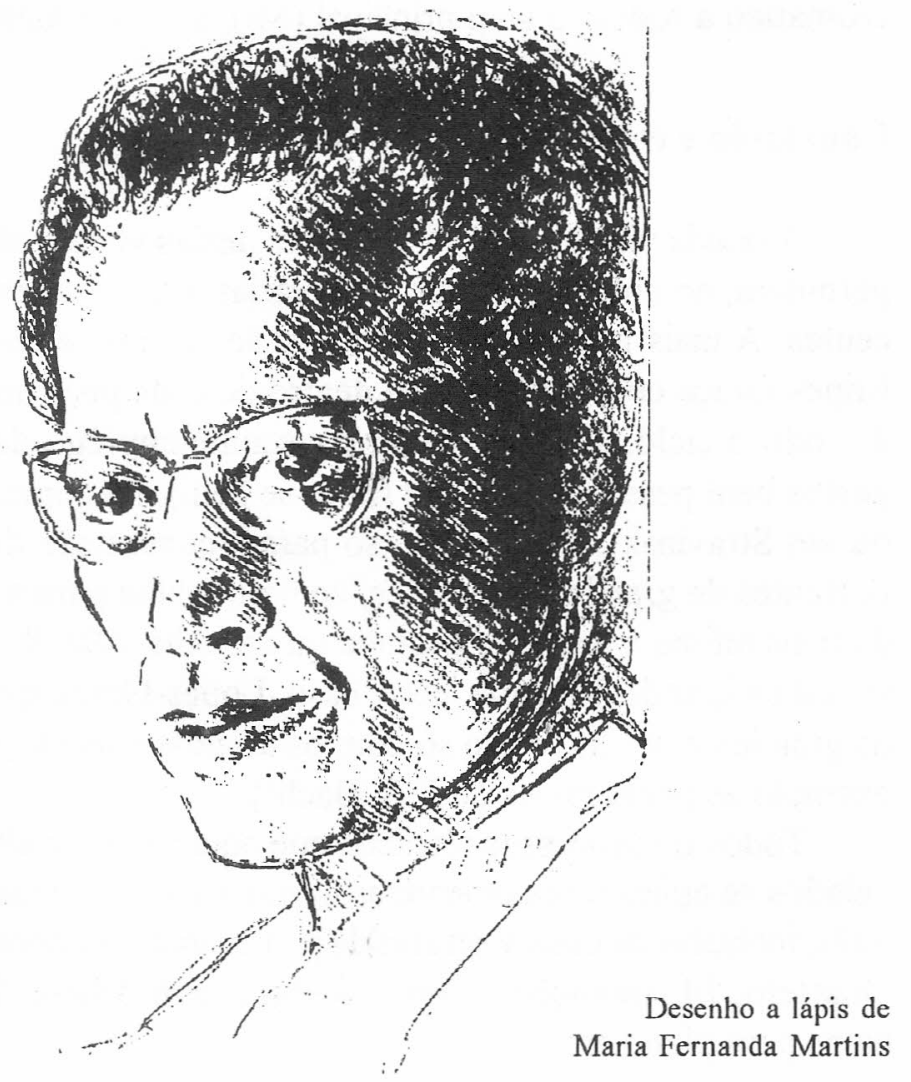




\section{PRODUÇÃO COMPOSICIONAL DE LOPES-GRAÇA}

* MÚSICA ORQUESTRAL - Três Danças Portuguesas; Sinfonia per orquestra; Suíte Rústica n. ${ }^{\circ}$; Cinco Estelas Funerárias; Poema de Dezembro; Divertimento; Para uma criança que vai nascer; Quatro bosquejos; Gabriela Cravo e Canela (abertura); Canto de Amor e de Morte (versão orquestral); Viagens na Minha Terra; Sinfonieta; Em louvor da Paz.

* MÚSICA CONCERTANTE - 2 Concertos para piano o orquestra; Concertino para piano, metais, cordas e percussão; Concertino para violeta; Concerto da cammera col violoncelo obligato.

* BAILADO - La Fièvre du temps (revista bailado); Dançares.

* MÚSICA DRAMÁTICA - D. Duardos e Flérida (cantata melodramática).

* MÚSICA CORAL SINFÔNICA - Requiem pelas vítimas do fascismo em Portugal.

* MÚSICA CORAL - Quatro redondilhas de Camões; Três líricas castelhanas de Camões; Balada duma heroína (Gomes Ferreira); Avisamento (Camões); Em louvor do Sol (Afonso Duarte); etc...; harmonizações de canções regionais portuguesas.

* CANTO E ORQUESTRA - História Trágico-Marítima; Nove canções populares portuguesas; Seis Cantos Sefardins.

* CANTO E CONJUNTO INSTRUMENTAL DE CÂMARA Cuatro canciones de Federico Garcia Lorca; Sete Predicações de "Os Lusíadas"; Nove Cantigas de Amigo.

* MÚSICA DE CÂMARA - 2 Quartetos de cordas; Suíte Rústica n. ${ }^{\circ}$ 2; Catorze Anotações para quarteto de cordas; Quarteto com piano; Canto de Amor e de Morte (para quarteto de cordas e piano); Sete Lembranças para Vieira da Silva (quinteto de sopros); O Túmulo de Villa-Lobos (quinteto de sopros); 2 Sonatinas para violino e piano; Tre Capriccelli para flauta e violão; Partita e Prelúdio e baileto para violão; Homenagem a Beethoven (3 equale para quatro contrabaixos). 
* MÚSICA DE PIANO - Variações sobre um tema popular português; 6 sonatas; Oito bagatelas; Glosas; 24 Prelúdios; Elegia; Melodias Rústicas Portuguesas; Cinco Nocturnos; In Memoriam Bela Bartok; Seis Improvisos; Ao Fio dos Anos e das Horas; etc...

* CANTO E PIANO - Canções sobre textos de: Antero de Quental, Casais Monteiro, Fernando Pessoa, José régio, Camões, Gomes Ferreira, Teixeira de Pascoaes, António Nobre, Afonso Duarte, Carlos de Oliveira, Almeida Garret, Eugénio de Andrade, Gil Vicente, Sá de Miranda, Bocage, Camilo Pessanha, Sophia de Mello Breyner, etc...; Canções regionais portuguesas; Marchas; Danças e Canções; Canções heróicas, dramáticas, bucólicas e outras; etc...

Antonio Sérgio Azevedo é Compositor, Professor Assistente na Escola Superior de Música de Lisboa, Universidade Nova de Lisboa e Academia Nacional Superior de Orquestra. 